\title{
СЛЕДСТВЕННЫЕ ДЕЙСТВИЯ ПО УСТАВУ УГОЛОВНОГО СУДОПРОИЗВОДСТВА
}

Аннотация: Анализируется система следственных действий по Уставу уголовного судопроизводства 1864 г., отражающая типичный ход предварительного расследования по уголовному делу того времени. Подчеркивается, что осмотр и освидетельствование обычно рассматривались как два вида (простое и сложное) одного действия, при возможности раздельного их осуществления, а процедуры обыска и выемки также свидетельствовали о двуедином понимании их сущности: как единого следственного действия и как действий самостоятельного значения. Предусматривались два вида допроса: обвиняемого и свидетеля, а проведение очной ставки было возможно только между ранее допрошенными свидетелями. Наряду с видами следственных действий в Уставе упоминались и их группы, имеющие собственное наименование: первоначальные, повторные, не терпящие отлагательства. В основе исследования системы следственных действий по Уставу уголовного судопроизводства использованы методы анализа, синтеза, обобщения, а также исторический, логический, сравнительный. В статье обосновывается, что решение современных проблем регламентации следственных действий возможно за счет использования прогрессивных достижений науки и фундаментальных разработок выдающихся дореволючионных ученых-процессуалистов. Отмечается, что согласно Уставу уголовного судопроизводства 1864 г. в ходе предварительного расследования проводились такие следственные действия, как осмотр, освидетельствование, обыск, выемка, допрос обвиняемого, свидетеля, отдельные правила которых могли бы быть полезны и сегодня. Указывается на отсутствие в тексте Устава термина "экспертиза», поскольку такая деятельность считалась разновидностью осмотра и освидетельствования. Предлагается рассматривать судебную экспертизу как следственное действие вопреки утверждениям отдельных авторов, что экспертиза не следственное, а процессуальное действие.

Ключевые слова: Устав, следственные, осмотр, освидетельствование, допрос, обыск, выемка, экспертиза, доказательства, повторные.

DOI: 10.7256/1994-1471.2014.4.11004

$\Pi$ о утверждению юристов Древнего Рима, история - учительница жизни (historia estmagis travitae). Действительно, не зная истории возникновения, становления и развития уголовно-процессуальных институтов, невозможно объективно подойти к решению современных актуальных проблем уголовного судопроизводства, включая институт следственных действий. Анализ предписаний УПК РФ 2001 г. показывает, что институт следственных действий подвергся существенным преобразованиям за счет прогрессивных достижений уголовно-процессуальной науки, фундаментальных разработок выдающихся дореволюционных, советских и постсоветских ученых-процессуалистов. Правда, по-прежнему остаются дискуссионными некоторые традиционные проблемы процессуальной регламентации следственных действий.
До сих пор в тексте УПК РФ отсутствует понятие следственных действий, что привело к истолкованию этой правовой категории либо в широком смысле, т. е. как всех тех действий, которые следователь осуществляет на основе уголовно-процессуального закона, либо в узком смысле, как действий познавательного характера. Нет ясности по вопросам о том, какова система следственных действий, закрепленная законодателем в названиях глав 2427? УПК РФ, сущность фактических и юридических оснований, условия и общие правила производства следственных действий, средства фиксации хода и результатов их производства. Эти и иные вопросы обусловливают актуальность исследования института следственных действий, в том числе путем обращения к тексту Устава уголовного судопроизводства 1864 г. (далее - Устав).

(C) Семенцов Владимир Александрович

* Доктор юридических наук, профессор кафедры уголовного процесса, Кубанский государственный университет

[crimpro@yandex.ru]

350000, Россия, г. Краснодар, ул. Рашпилевская, д. 43. 
Достоинство Устава - прогрессивный характер его идей, когда на смену инквизиционному розыскному процессу пришел процесс состязательный, основанный на свободной оценке судом доказательств, рассмотренных в ходе гласного судебного разбирательства. Впервые в России был применен системный подход к формированию института следственных действий как упорядоченного, внутренне согласованного и взаимообусловленного комплекса процессуальных действий, направленных на собирание и проверку доказательств.

В Уставе следственные действия компактно закреплены во втором разделе «0 предварительном следствии», в нескольких его главах четвертой, пятой и седьмой, а в главах второй и девятой определены соответственно условия производства предварительного следствия, включая производство следственных действий, и правила их протоколирования. Следственные действия регламентировались в логической последовательности, отражающей типичный ход предварительного расследования по уголовному делу, - осмотр, освидетельствование, обыск, выемка, допрос обвиняемого, свидетеля. К сожалению, законодатель того времени не установил компактного и исчерпывающего перечня следственных действий. Этот недостаток, как справедливо отмечается в литературе ${ }^{1}$, стал «хроническим» для последующих российских уголовно-процессуальных кодексов, что приводило и приводит в настоящее время к затяжным дискуссиям ученых по этому вопросу и в определенной степени дезориентирует практику.

Вместе с тем ни в Уставе, ни в его толкованиях Сенатом, объединяющим и направляющим всю деятельность судебных учреждений «по правильному и единообразному применению законов», не было дано определений понятий осмотра, освидетельствования, обыска и выемки.

При этом осмотр и освидетельствование рассматривались как два вида (простое и сложное) одного действия, которые обычно дополняли друг друга, но могли осуществляться и раздельно. Понятие «освидетельствование» трактовалось как квалифицированный вид осмотра, осмотр-исследование, о чем свидетельствуют предписания ст. 330 Устава, где предусмотрено, что перед тем как приступить к «освидетельствованию... чрез сведущих людей, судебный следователь производит предварительный внешний осмотр».

Трухачев В.В., Барсукова Т.В. Возникновение и развитие системы следственных действий // Комплексные меры - ключевой фактор стабилизации производства и решения социальных проблем: сб. науч. тр.: в 2 ч. Воронеж: Истоки, 2003. Ч. 2. С. 37.
Не было единства мнений у авторитетных ученых при формулировании дефиниций понятий «обыск» и «выемка». Так, И.Я. Фойницкий считал, что «осмотр, производящийся в жилых помещениях, получает техническое название обыска. Выемка есть взятие каких-либо предметов внешнего мира для приобщения их к делу, производящееся обыкновенно при обыске, но возможное и независимо от обыска» ${ }^{2}$.

П.В. Макалинский полагал, что «обыск есть розыскание в известном, определенном месте скрываемых обвиняемых или предметов, необходимых для разъяснения состава преступления и виновности или невиновности обвиняемого, а выемка - последствие обыска, взятие найденного» ${ }^{3}$.

В.К. Случевский отмечал, что «действия, предпринимаемые органами следственной власти с целью разыскания... вещественных доказательств, выражаются в обысках, а также выемках, как результат их» ${ }^{4}$

Анализ закрепленной в Уставе процедуры обыска и выемки, позиций ученых того времени позволяет сделать вывод о двуедином понимании их сущности: 1) как единого следственного действия, когда обыск осуществлялся для отыскания предметов, имеющих значение для дела, или самого обвиняемого, а выемка для изъятия обнаруженного при обыске; 2) как действий самостоятельного значения, когда обыск можно было провести без выемки, а выемку - без обыска, о чем свидетельствуют правила ст. 359 и 371 Устава, где обыск и выемка упоминаются с использованием разделительного союза «или», и ст. 267 Устава, регламентировавшей порядок выемки вещественных доказательств.

Законом от 30 октября 1878 г. Устав был дополнен ст. 368.1, предоставившей следователю право осмотра и выемки корреспонденции с санкции окружного суда и в присутствии должностного лица почтово-телеграфного ведомства. Причем допускались осмотр и выемка только той корреспонденции, которая поступала от имени или на имя лиц, привлеченных к уголовному делу в качестве обвиняемых.

В Уставе предусматривались два вида допроса: обвиняемого (ст. 398-414) и свидетеля (ст. 433-453).

В соответствии со ст. 398 Устава первоначальный допрос обвиняемого производился

2 Фойницкий И.Я. Курс уголовного судопроизводства: в 2 т. СПб., 1996. Т. 2. С. 322.

3 Макалинский П.В. Практическое руководство для судебных следователей. 6-е изд. СПб., 1907. С. 326.

4 Случевский В.К. Учебник русского уголовного процесса. Ч. 2: Судопроизводство / под ред. В.А. Томсинова. М.: Зерцало, 2008. С. 50. 
немедленно либо не позже суток после его явки или привода, «чтобы не оставлять его продолжительное время под стражей в неизвестности, за что он подвергнут задержанию, и чтобы дать ему возможность, если он задержан неправильно, разъяснить эту неправильность» ${ }^{5}$. Нарушение установленного в законе суточного срока допроса обвиняемого рассматривалось как серьезный проступок и влекло ответственность по ст. 430 Уложения о наказаниях вплоть до отрешения от должности. Если допрос обвиняемого «не был сделан в течение первых двенадцати часов после явки или привода», то причины отсрочки следовало указать в протоколе, копия которого выдавалась обвиняемому по его требованию (ст. 399 Устава).

Предписания ст. 410 Устава о том, что «к допросу обвиняемого, объясняющегося на языке, не понятном для судебного следователя, приглашается лицо, сведущее в этом языке», истолковывались как наделяющие следователя, для которого язык был понятен, правом выступать в качестве переводчика, с записью в протоколе показаний обвиняемого на русском языке.

Процедура допроса свидетеля осуществлялась по правилам, отдельные из которых могли бы быть полезны и сегодня. Так, в ст. 437 Устава отмечалось, что «для явки свидетелей назначается, по возможности, время, в которое они свободны от занятий», в ст. 434 рекомендовалось производить «допрос многих свидетелей, находящихся в одном околотке... в том месте, где они находятся», а в соответствии со ст. 438 привод свидетеля при отсутствии законных причин неявки осуществлялся после повторной неявки.

Свои показания свидетель давал следователю под присягой или без присяги. Свидетель приводился к присяге в трех случаях: 1) если он собрался в дальний путь и возвращение может замедлиться; 2) находится в болезненном состоянии, угрожающем опасностью его жизни; 3) имеет жительство вне округа того суда, которому подсудно дело, и притом такой отдаленности от места судебных заседаний, что ему без особенного затруднения явиться в суд невозможно (ст. 442 Устава). В остальных случаях судебный следователь не приводил свидетеля к присяге, а лишь разъяснял ему необходимость «показать всю правду по чистой совести» (ст. 443 Устава).

В ст. 452 Устава, размещенной в главе седьмой «0 вызове и допросе свидетеля», устанав-

\footnotetext{
Судебные уставы 20 ноября 1864 г., с изложением рассуждений, на коих они основаны, изданные Государственной канцелярией: в 5 ч. 2-е изд., доп. и изм. СПб. 1867. Ч. 2. С. 153.
}

ливались отдельные правила очной ставки, проводимой между ранее допрошенными свидетелями для «разъяснения противоречий в их показаниях», от которых «зависит дальнейшее направление следствия». Поскольку обвиняемый имел право присутствовать при допросе свидетеля (ст. 446, 448 Устава), то признавалось излишним проведение очной ставки между ним и свидетелем, а также, как разъяснил Сенат, в случае его присутствия при допросе других обвиняемых. А вот об очных ставках с участием потерпевших ничего не говорилось ни в законе, ни в его толкованиях.

В тексте Устава не применялся термин «экспертиза», поскольку, по мнению его составителей, экспертиза не может рассматриваться как самостоятельное следственное действие. Вместо него использовались иные понятия: «осмотр и освидетельствование чрез сведущих людей вообще» (ст. 325-335), «осмотр и освидетельствование чрез врачей» (ст. 336-352), «освидетельствование обвиняемого, оказавшегося сумасшедшим или безумным» (ст. 353356), а лицо, проводившее такие осмотр и освидетельствование, опять же не именовалось экспертом, хотя и должно было быть сведущим в науке, искусстве, ремесле, промысле или каком-либо занятии.

Были сформулированы основные требования к сведущим лицам: «иметь все качества достоверных свидетелей» (ст. 326), т. е. незаинтересованность в исходе дела; возможность проявления инициативы в целях установления «признаков, на которые следователь не обратил внимание, но исследование коих может привести к открытию истины» (ст. 333), формулирование результатов исследования в заключении (ст. 334) и др.

В то же время в циркуляре Министерства юстиции от 10 января 1877 г. предписывалось помещать экспертов (заметим, не сведущих лиц, а именно экспертов) не в общий список свидетелей, подлежащих вызову в суд, а в особый список. В циркуляре Министерства юстиции от 17 февраля 1879 г. сообщалось, что старшим председателям судебных палат и председателям окружных судов выделяется аванс в сумме 300 руб. на расходы по оплате экспертов, вызываемых в суды по уголовным делам. В циркуляре Министерства юстиции от 21 мая 1870 г. отмечалось, что вопрос о выдаче вознаграждения экспертам, вызывавшимся к судебному следователю, подлежит разрешению «тотчас же по получении от него счета, не ожидая окончательного решения дела по существу» ${ }^{6}$.

Российское законодательство X-XX веков. Т. 8: Судебная реформа. М.: Юрид. лит., 1991. С. 317, 349, 350. 
Отсутствие в тексте Устава указания на такой познавательный прием, как экспертиза, встретило серьезную критику еще в русской дореволюционной литературе, и к тому были объективные основания: закон подробно регламентировал порядок проведения предшественников современных медицинских, психиатрических, химических и других видов экспертиз, хотя такая деятельность считалась разновидностью осмотра и освидетельствования, а к заключению эксперта относились как к свидетельским показаниям.

Несмотря на то, что в тексте Устава термин «экспертиза» не использовался, а лицо, проводившее исследование, именовалось экспертом лишь в циркулярах Министерства юстиции, возможность широкого использования научных познаний сыграла позитивную роль в повышении эффективности предварительного следствия и судебного разбирательства по уголовным делам, обусловила необходимость решения организационных проблем, связанных с созданием сети экспертных учреждений. 28 июля 1912 г. был принят закон о создании в России первого специализированного судебноэкспертного учреждения - кабинета научносудебной экспертизы. При этом использовался опыт работы судебно-фотографической лаборатории, учрежденной в 1893 г. при прокуратуре Санкт-Петербургской судебной палаты, и экспертных учреждений Европы ${ }^{7}$.

Постепенно в среде ученых стало преобладать мнение об экспертизе как самостоятельном виде доказательств (С.И. Викторский, М.В. Духовской, Н.Н. Рогозин, В.К Случевский). Например, С.И. Викторский писал: «Наши законы смотрят на экспертизу как на самостоятельный вид доказательств, что явствует из следующего: 1) в них нет постановлений об обязательном совпадении осмотра с экспертизой; 2) в них имеется запрещение спрашивать свидетеля, какого он мнения о факте; 3) заключение экспертов по ним подлежит контролю и свободной судейской оценке» 8 .

И.Я. Фойницкий отмечал: «Не будучи ни судебным решением, ни видом осмотра, ни, наконец, особым видом свидетельского показания, экспертиза представляется особым судебным доказательством. Она есть доказательство, потому что экспертиза частью дает известным суду обстоятельствам новое освещение, выясняющее их истинное значение, частью при помощи употребляемых ею

Россинская Е.Р., Галяшина Е.И., Зинин А.М. Теория судебной экспертизы: учеб. / под ред. Е.Р. Россинской. М.: Норма, 2009. С. 23.

Викторский С.И. Русский уголовный процесс. М., 1997. С. 295. приемов обнаруживает и раскрывает перед судом обстоятельства, которые остались ему неизвестными» 9 .

Сегодня уже нет сомнений в самостоятельном доказательством значении заключения эксперта, которое, однако, «не имеет заранее установленной силы, не обладает преимуществом перед другими доказательствами и, как все иные доказательства, оценивается по общим правилам в совокупности с другими доказательствами» ${ }^{10}$.

Современный законодатель рассматривает судебную экспертизу как «процессуальное действие, состоящее из проведения исследований и дачи заключения экспертом по вопросам, разрешение которых требует специальных знаний в области науки, техники, искусства или ремесла и которые поставлены перед экспертом судом, судьей, органом дознания, лицом, производящим дознание, следователем, в целях установления обстоятельств, подлежащих доказыванию по конкретному делу» ${ }^{11}$.

Законодательное определение судебной экспертизы как процессуального действия послужило основанием для утверждения, что судебная экспертиза - не следственное действие. Так, С.Б. Россинский считает, что судебную экспертизу нельзя отождествлять со следственными действиями по трем причинам: во-первых, следственные действия осуществляются самим следователем, а судебная экспертиза особым субъектом уголовно-процессуальной деятельности - экспертом; во-вторых, судебные экспертизы, в отличие от следственных действий, всегда связаны с использованием специальных знаний и проводятся в том случае, когда без их применения невозможно установить те или иные значимые для уголовного дела обстоятельства; в-третьих, результаты судебной экспертизы оформляются не протоколом, а специальным процессуальным документом - заключением эксперта ${ }^{12}$.

Следователь, действительно, не проводит исследование, поскольку уполномочен собирать доказательства, но не создавать их. Именно поэтому порядок проведения исследования

\section{9 Фойницкий И.Я. Указ. соч. С. 289.}

10 П. 19 постановления Пленума Верховного Суда РФ «О судебной экспертизе по уголовным делам» от 21 декабря 2010 г. № 28 // Российская газета. 2010. 30 декабря.

11 Ст. 9 Федерального закона «О государственной судебно-экспертной деятельности в Российской Федерации» от 31 мая 2001 г. № 73-ФЗ (с изм. на 25 ноября 2013 г.) // Собрание законодательства РФ. 2001. № 23. ст. 2291; Собрание законодательства РФ. 2013. № 48. ст. 6165.

12 Россинский С.Б. Уголовный процесс: учебник. М.: Эксмо, 2009. С. 415-416. 
нормами УПК РФ не регламентируется. В то же время следователь назначает судебную экспертизу и в ходе исследования обеспечивает реализацию обширного комплекса уголовнопроцессуальных правоотношений, участниками которых является он сам, а также эксперт, подозреваемый, обвиняемый, защитник, потерпевший и свидетель.

Процедурные правила назначения и производства судебной экспертизы завершают в разделе VIII УПК РФ систему следственных действий. Объем этих правил столь велик, что вызвал необходимость их регламентации в рамках отдельной главы. Судебная экспертиза отвечает общим требованиям, предъявляемым законом к следственным действиям.

Производство судебной экспертизы связано с использованием специальных познаний, как справедливо отмечает С.Б. Россинский, но это присуще и другим следственным действиям. Следователь по своему усмотрению может привлечь к участию в любом следственном действии лицо, обладающее специальными познаниями (ст. 168 УПК РФ). Если лицо, обладающее специальными познаниями, назначено в установленном законом порядке для производства судебной экспертизы, то его процессуальное положение - эксперт. Использование специальных познаний обязательно не только при судебной экспертизе, но и при осмотре трупа и эксгумации (чч. 1, 4 ст. 178 УПК РФ), освидетельствовании (чч. 3, 4 ст. 179 УПК РФ.

Что касается процессуальной формы судебной экспертизы, то это не только заключение эксперта, но и постановление следователя о назначении судебной экспертизы, протоколы ознакомления заинтересованных участников с указанным решением, постановление и протокол получения образцов для сравнительного исследования, протокол допроса эксперта.

Вызывает также возражение утверждение отдельных авторов о том, что эксперт не участник процесса, не субъект процессуальной деятельности: он источник получения доказательств, его заключение является доказательством наряду с другими (показаниями свидетелей, документами и др. $)^{13}$. В разделе II УПК РФ, именуемом «Участники уголовного судопроизводства», в числе иных участников назван эксперт, процессуальное положение которого регламентируется в ст. 57 УПК РФ. Эксперт, как и любой иной участник уголовного судопроизводства, наделен рядом процессуальных

13 Сорокотягина Д.А., Сорокотягин И.Н. Судебная экспертиза (экспертология): учеб. пособие. Екатеринбург, 2000. C. 16. прав, позволяющих ему выполнить должным образом свою функцию. Обязанности эксперта сформулированы в форме запрета совершать определенные действия. Предусмотрена и ответственность за заведомо ложное заключение, разглашение данных предварительного расследования.

Кроме того, следует иметь в виду, что определение в законе «0 государственной судебно-экспертной деятельности в Российской Федерации» судебной экспертизы как процессуального действия соответствует предписанием п. 32 ст. 5 УПК РФ, где следственные действия указаны как разновидность процессуальных действий.

Таким образом, с нашей точки зрения, судебная экспертиза есть следственное действие, состоящее в поручении лицу, обладающему специальными познаниями в науке, технике, искусстве или ремесле (эксперту), произвести исследование выявленных при проверке сообщения о преступления и (или) расследовании уголовного дела материалов и дать заключение по вопросам, имеющим значение для установления обстоятельств, подлежащих доказыванию.

А теперь рассмотрим еще один момент, связанный с тем, что в системе следственных действий традиционно выделяются не только самостоятельные их виды, но и группы, имеющие собственное наименование. Для этого вновь обратимся к анализу Устава, где можно найти указания законодателя на группу первоначальных (имеющих целью получение первичных сведений) и повторных следственных действий (имеющих ту же цель, что и ранее выполненные).

В частности, применительно к допросу обвиняемого в ст. 398 Устава используется термин «первоначальный», а в ст. 412 закреплено, что «к повторению допросов судебный следователь не должен прибегать без особой в том надобности». Из содержания ст. 446 и 451 Устава следует, что «если окажется нужным», то первоначально свидетели допрашиваются «в отсутствие обвиняемых и прикосновенных к делу лиц», а «в случае необходимости следователь может передопросить свидетеля». О возможности проведения повторного освидетельствования упоминается в ст. 345 и 346 Устава.

Отсутствие в Уставе, как, впрочем, и в ныне действующем УПК РФ, указания на возможность повторного производства некоторых других следственных действий, не исключало повторного проведения осмотра места происшествия и обыска.

В современной системе следственных действий принято выделять группу следственных 
действий, именуемых неотложными. В отечественном дореволюционном уголовно-процессуальном законодательстве это понятие отсутствовало (впервые термин «неотложные следственные действия» появился в ст. 29 Основ уголовного судопроизводства Союза ССР и союзных республик 1958 г.). Вместе с тем ст. 258 Устава предусматривала следственные действия, не терпящие отлагательства. Полиции предписывалось в случаях, когда «застигнуто совершающееся или только совершившееся преступное деяние», а «следы преступления могли бы изгладиться», заменять судебного следователя в осмотрах, освидетельствованиях, обысках и выемках.

В то же время полиции запрещалось допрашивать свидетелей, обвиняемых, за исключением случаев, когда «кто-либо из них оказался тяжко больным и представилось бы опасение, что он умрет до прибытия следователя». По этому поводу составители судебных уставов отмечали следующее: «по важности формальных допросов, производство их должно быть отнесено к обязанностям судебных следователей, а не полицейских чинов, от которых не требуется качеств, необходимых для судьи, а снятие допросов принадлежит к действиям чисто судебного свойства» ${ }^{14}$.

Вследствие запрета на производство допроса полиция не имела права на вызов и привод свидетеля, который не обязан был давать показания полиции, действующей как орган дознания. Полиция даже не имела права на составление какого-либо протокола, в котором показания были бы засвидетельствованы подписью иных, кроме дознавателя, лиц. В инструкции прокуроров судебных палат чинам полиции предписывалось: «Сведения, собранные полицией при дознании, заносятся с указанием источника, из которого они получены, в один общий акт, за подписью только одного должностного лица, производившего дознание» ${ }^{15}$.

Несмотря на это полиция стремилась к составлению протоколов, подписанных свидетелями и иными лицами, «для того чтобы оградить себя от нареканий или обвинений в неправильности действий» ${ }^{16}$, но показания, записанные в таких протоколах, нередко опровергались на следствии и на суде.

Подводя итог рассмотрению вопроса о системе следственных действий по Уставу уго- ловного судопроизводства 1864 г., можно сделать следующие выводы.

1. Решение современных актуальных проблем регламентации следственных действий возможно за счет использования прогрессивных достижений науки и фундаментальных разработок выдающихся дореволюционных ученых-процессуалистов, когда в России впервые был применен системный подход к формированию института следственных действий.

2. В Уставе следственные действия регламентировались в логической последовательности, отражающей типичный ход предварительного расследования, - осмотр, освидетельствование, обыск, выемка, допрос обвиняемого, свидетеля, но без формулирования их понятий.

3. Осмотр и освидетельствование обычно рассматривались как два вида (простое и сложное) одного действия, при возможности раздельного их осуществления, а процедуры обыска и выемки также свидетельствовали о двуедином понимании их сущности: как единого следственного действия и как действий самостоятельного значения.

4. Отдельные правила допроса свидетеля могли бы быть полезны и сегодня: о назначении явки свидетелей «по возможности, на время, в которое они свободны от занятий», о «допросе многих свидетелей, находящихся в одном околотке... в том месте, где они находятся», о приводе свидетеля «после повторной неявки». Согласно Уставу проведение очной ставки было возможно только между ранее допрошенными свидетелями.

5. В тексте Устава термин «экспертиза» не использовался, а лицо, проводившее исследование, именовалось экспертом лишь в циркулярах Министерства юстиции. Такая деятельность считалась разновидностью осмотра и освидетельствования, но постепенно в среде ученых стало преобладать мнение об экспертизе как самостоятельном доказательстве. Сегодня судебная экспертиза отвечает общим требованиям, предъявляемым законом к следственным действиям.

6. Наряду с видами следственных действий в Уставе упоминались и их группы, имеющие собственное наименование: первоначальные, повторные, не терпящие отлагательства.

14 Судебные уставы 20 ноября 1864 г., с изложением рассуждений... Ч. 2. С. 118.

15 Муравьев Н.В. Инструкция чинам полиции округа

С. - Петербургской судебной палаты. СПб., 1884. С. 5.

16 Макалинский П.В. Указ. соч. С. 34. 


\section{Библиография}

1. Трухачев В.В., Барсукова Т.В. Возникновение и развитие системы следственных действий // Комплексные меры - ключевой фактор стабилизации производства и решения социальных проблем: сб. науч. тр.: в 2 ч. Воронеж: Истоки, 2003.

2. Фойницкий И.Я. Курс уголовного судопроизводства: в 2 т. СПб., 1996. Т. 2.

3. Макалинский П.В. Практическое руководство для судебных следователей. 6-е изд. СПб., 1907.

4. Случевский В.К. Учебник русского уголовного процесса. Ч. 2: Судопроизводство / под ред. В.А. Томсинова. М.: Зерцало, 2008.

5. Россинская Е.Р., Галяшина Е.И., Зинин А.М. Теория судебной экспертизы: учеб. / под ред. Е.Р. Россинской. М.: Норма, 2009.

6. Викторский С.И. Русский уголовный процесс. М., 1997.

7. Россинский С.Б. Уголовный процесс: учебник. М.: Эксмо, 2009.

8. Сорокотягина Д.А., Сорокотягин И.Н. Судебная экспертиза (экспертология): учеб. пособие. Екатеринбург, 2000.

9. Муравьев Н.В. Инструкция чинам полиции округа С. - Петербургской судебной палаты. СПб., 1884.

\section{References}

1. Trukhachev V.V., Barsukova T.V. Vozniknovenie i razvitie sistemy sledstvennykh deistvii // Kompleksnye mery - klyuchevoi faktor stabilizatsii proizvodstva i resheniya sotsial'nykh problem: sb. nauch. tr.: v 2 ch. Voronezh: Istoki, 2003.

2. Foinitskii I.Ya. Kurs ugolovnogo sudoproizvodstva: v 2 t. SPb., 1996. T. 2.

3. Makalinskii P.V. Prakticheskoe rukovodstvo dlya sudebnykh sledovatelei. 6-e izd. SPb., 1907.

4. Sluchevskii V.K. Uchebnik russkogo ugolovnogo protsessa. Ch. 2: Sudoproizvodstvo / pod red. V.A. Tomsinova. M.: Zertsalo, 2008.

5. Rossinskaya E.R., Galyashina E.I., Zinin A.M. Teoriya sudebnoi ekspertizy: ucheb. / pod red. E.R. Rossinskoi. M.: Norma, 2009.

6. Viktorskii S.I. Russkii ugolovnyi protsess. M., 1997.

7. Rossinskii S.B. Ugolovnyi protsess: uchebnik. M.: Eksmo, 2009.

8. Sorokotyagina D.A., Sorokotyagin I.N. Sudebnaya ekspertiza (ekspertologiya): ucheb. posobie. Ekaterinburg, 2000.

9. Murav'ev N.V. Instruktsiya chinam politsii okruga S. - Peterburgskoi sudebnoi palaty. SPb., 1884. 